\title{
Lack of C-erbB-2 protein expression in pulmonary carcinoid tumours
}

\author{
N Wilkinson, P S Hasleton, S Wilkes, A Quigley
}

\begin{abstract}
To determine if amplification of the $C$ erb-B2 proto-oncogene could be correlated with prognosis in carcinoid tumours, 49 pulmonary carcinoid tumours (26 typical, 23 atypical) were examined using a polyclonal antibody to the C-terminal peptide of the $C$-erb-B2 protein sequence. No $C$-erb-B2 gene product could be shown: the demonstration of $C$-erb-B2 does not seem to help, therefore, in determining diagnosis or prognosis in pulmonary carcinoid tumours.
\end{abstract}

$C$-erbB-2 is a proto-oncogene present on chromosome $17^{1}$ which encodes a 18.5 kilodalton transmembrane glycoprotein with tyrosine kinase activity. ${ }^{2}$ Amplification of the $C-e r b B-2$ gene has been seen in gastric ${ }^{3}$ and breast carcinomas. In the latter, amplification has been correlated with relapse and survival. ${ }^{4}$ Gene amplification has been shown to be closely associated with immunohistochemical assessment of the gene product in both frozen and paraffin wax embedded material..$^{5}$ We were interested to see if immunohistochemical assessment of the $C$-erbB-2 gene product would be of value as a prognostic indicator in carcinoid tumours of the lung.

We therefore looked at 49 formalin fixed, paraffin wax embedded carcinoid tumours of the lung, of which 26 were typical and 23 were atypical, using a polyclonal antibody to the Cterminal peptide of the $C-e r b B-2$ protein sequence. ${ }^{6}$ The antibody was kindly provided by Dr B Gullick, Imperial Cancer Research Fund, London. A breast carcinoma known to be positive for the $C-e r b B-2$ oncoprotein was used as the positive control and primary antibody was omitted as the negative control. The primary antibody was used at a concentration of $5.2 \mu \mathrm{g} / \mathrm{ml}$ and sections were kept at $4^{\circ} \mathrm{C}$ overnight. The sections were washed in phosphate buffered saline (PBS) the next day and then incubated for an hour with secondary antiserum (biotinylated swine anti-rabbit immunoglobulin) (Dakopatts) at a dilution of 1 in 100 in PBS. After further washing in TRIS-buffered saline (TBS) the sections were treated for 60 minutes with swine antirabbit ( 1 in 100 dilution). A further wash for $30 \mathrm{~min}$ utes in TBS was followed by peroxidase antiperoxidase ( 1 in 100) for 60 minutes, then a further wash in TRIS buffered saline for 30 minutes. Peroxidase activity was shown using diamino-benzidine solution. Nuclei were counterstained with haematoxylin.

The breast carcinoma showed focal strong membrane staining of the malignant cells with some diffuse, granular, cytoplasmic staining. All the 49 carcinoid tumours, however, were negative. Diffuse cytoplasmic staining of bronchial chondrocytes was noted in some sections, but no membrane staining was observed.

This study shows that $C$-erbB-2 oncoprotein is not expressed by carcinoid tumours of the lung and therefore immunohistochemical assessment of the $C-e r b B-2$ gene product is of no value in determining diagnosis or prognosis.

1 Fukushige SI, Matsubara KI, Yoshida M, et al. Localisation of a novel V-erbB related gene, C-erbB-2, on human chromosome 17 and its amplification in a gastric cancer cell line. Mol Cell Biol 1986;6:955-8.

2 Akiyama T, Sudo C, Ogawara H, Toyoshima K, Yamamoto T. The product of the human C-erbB-2 gene: A 185 kilodalton glycoprotein with tyrosine kinase activity. kilodalton glycoprotein
Science 1986;232:1644-6.

3 Yokota J, Yamamoto T, Toyoshima K, et al. Amplification of C-erbB-2 oncogene in human adeno-carcinoma in vivo. Lancet 1986; i:765-6.

4 Slamon DJ, Clark GM, Wong SA, Levin WJ, Ullrich A, McCurrie WL. Human breast cancer: correlation of relapse and survival with amplification of the HER-z/neu oncogene. Science 1987;235:177-82.

5 Venter DJ, Kumar S, Tuzi NL, Gullick WJ. Overexpression of the C-erbB-2 oncoprotein in human breast carcinomas-immunohistochemical assessment correlates with gene amplification. Lancet 1987;ii:69-72.

6 Gullick WJ, Berger MS, Bennett PLP, Rothbard JB, Waterfield MD. Expression of the C-erbB-2 protein in normal and transformed cells. Int J Cancer 1987;40: 246-54. 